\title{
En busca de modelos construidos con la razón y con la historia
}

\author{
Carlos Pereda
}

En sus admirables notas en torno a mi libro Vértigos argumentales, Sergio Martínez con su habitual perspicacia percibe "un titubeo": cierta indecisión no sólo en algunos de mis argumentos sino en el consistiria básicamente en no querer abandonar con la resolución requerida lo que Martínez llama el "programa analítico", el "dogma analítico", en particular en lo que atane al dilema: o bien hay normas de razonamiento universales, independientes de cualquier contexto, o bien no hay norma posible. Este dilema parece ser una de las tantas aplicaciones del mecanismo del todo o nada, o mejor, de la sofística del todo o nada. Martínez piensa que no podemos dar ni siquiera un paso hacia una epistemología sana y promisoria si antes, con energía, no nos libramos de dicho dilema; tal es así que estoy tentado en llamarlo "el obstáculo de Martínez" en relación con la epistemología. Ese obstáculo tendría ramificaciones incluso inesperadas que a quien lo aceptase llegarían hasta obligarlo o bien a defender una epistemología naturalizada puramente descriptiva (la espistemología reducida a psicología, sociología o historia del saber, entendidas cada una de esas disciplinas de la manera más contingentemente empirista) o bien se tendría que abrazar una epistemología puramente a priori, inmune a las vicisitudes de la geografia y de la historia. Esto es, o habría historia y una sucesión de enredadas contingencias sin ton ni son o habria razón y estructura y necesidad y argumentos trascendentales.

Sin embargo, ¿hay que deshacerse del obstáculo de Martínez y, por ejemplo, descreer de cualquier norma necesariamente universal? $O$, más bien, ¿podemos deshacernos sin más del obstáculo de Martínez y defender que toda norma es, en algún sentido, contextual? ¿Tomar demasiado en serio el obstáculo de Martínez no nos conduce inevitablemente a cierto autocontradictorio relativismo psicologista, sociologista o historicista? ¿Cómo po- 
driamos caracterizar y hasta concebir una normatividad epistemológica que abandone toda pretensión de universalidad?

2. Sospecho que hay, por lo menos, dos modos de superar el obstáculo de Martínez, o al menos, de que el obstáculo de Martínez nos deje en paz. El primer modo sería pensar que todas las normas en última instancia son normas contextuales, surgidas en algún momento de la historia y, luego, por alguna razón, (icontextualmente?) atrincheradas (pero ese atrincheramiento ¿se produciría por razones de mero interés contextual, o qué otras razones habría que tener en cuenta al respecto, además de la utilidad inmediata? ¿Y esos atrincheramientos serían irreversibles o no? Y si lo fueran ¿con qué razones diriamos que lo son?). A este modo, teniendo en cuenta su decisión para abandonar todo vestigio de universalidad y hasta de necesidad, podríamos llamarlo el modo puro de liberarnos del obstáculo de Martínez. Creo que Sergio Martínez algunas veces tiende a favorecer este modo puro de liberación del dilema.

Por el contrario, un modo impuro sería aquel que procurase teorías y modelos mixtos, en parte universales, en parte contextuales; $o$ incluso, con mayor riesgo, se buscaría obtener teorías y modelos mixtos, en parte trascendentales, en parte históricos. Pero ipuede haber esas teorías y modelos mixtos?, ¿no descansan meramente en confusiones?, ¿no conforman sólo engendros imaginarios, construcciones por yuxtaposición como el centauro, pero sin ningún posible referente real? El modelo de la disputatio que traté de exponer y defender en Vértigos argumentales procura ser un modelo mixto. ¿En qué sentido?

En el capítulo I, "Esbozo de una teoría elemental de la argumentación" -evitando caer en cualquier vértigo prescriptivista-, propongo reconstruir la argumentación como una totalidad articulada por ciertas reglas. Según cómo rigen distingo entre reglas constitutivas y regulativas; según qué rigen distingo entre reglas morfológicas, inferenciales y procedimentales. Dejemos de lado - por el momento- las reglas inferenciales. Las reglas morfológicas constitutivas -como lo expresa el sentido mismo de reglas "constitutiva"definen lo que es un diálogo: indica que debe haber un proponente y tener ciertas funciones, que debe haber un oponente también con ciertas funciones, un problema que se disputa. En cierto sentido, podemos decir que se trata de condiciones de posibilidad estructurales de cualquier diálogo, de reglas, pues, no sólo empíricamente universales sino necesariamente universales: de reglas trascendentales. Alli donde hay una argumentación tiene que haber esos "roles" y los otros elementos, de lo contrario no habría argumentación.

Se objetará: esas reglas constitutivas dicen muy poco; más todavía, casi, casi no nos dicen nada. Son las reglas regulativas las que "instancian", las que 
hacen "encarnar" las reglas constitutivas. Las virtudes morfológicas son virtudes que deben poseer el proponente, el oponente y el juez o virtudes personales, por un lado, y por otro, virtudes que tiene que tener el planteamiento de un problema. Esas virtudes son claramente resultado de ciertos aprendizajes históricos: son virtudes históricas, es decir, propiedades que se han "atrincherado" en la historia y que en varios grados promueven comprensión, verdad y/o valor. (Las virtudes personales que se introducen en Vértigos son integridad epistémica, rigor y espiritu de rescate, siendo las dos últimas también virtudes del planteamiento de un problema.)

Algo similar, creo, sucede con las reglas procedimentales. Las reglas procedimentales constitutivas son las reglas de presunción. Las reglas de presunción poseen todas la forma: actúa como si $x$, a menos que haya razones particulares $r_{1}, r_{2} \ldots r_{n}$ en contra de $x$. Los valores de la variable $x$ son com. prensión, verdad y valor. De este modo, tenemos que una comunicación no se constituye sin la presunción de comprensión y una argumentación no se constituye sin las presunciones de verdad y valor. Así, a diferencia de una presunción jurídica como "cualquier acusado de un crimen es inocente hasta que se demuestre su culpabilidad", estas presunciones son condiciones de posibilidad funcionales de cualquier argumentación $\mathrm{y}$, por lo tanto, se trata de reglas universales y necesarias si es que queremos comunicarnos y argumentar.

De nuevo se podría objetar que estamos todavía diciendo muy poco. En primer lugar, qué significa de caso en caso cada una de estas presunciones, depende del contexto preciso en que se lleva a cabo el debate. Por ejemplo, la presunción de comprensión tendrá un contenido muy diferente en un debate entre amantes, entre políticos o entre físicos, entre otras razones, todas estas personas entenderán por "precisión" algo muy diferente; sin embargo, parecería que en todos estos debates tendrian que cumplirse al menos en un grado mínimo el principio de identidad y el principio de no contradicción, so pena de que, en ausencia de ello, no se entendiese nada. Y hay diferentes maneras de comprender estos principios pero no tenemos alternativas a ellos. La presunción de verdad posee dos dimensiones totalmente opuestas: la verdad "subjetiva" o veracidad (sinceridad), por un lado, y la verdad "objetiva", o decir efectivamente lo que es el caso, por otro; la primera se opone a la mentira, la segunda a la falsedad. En cuanto a la presunción de valor nítidamente "se dice de muchas maneras".

A su vez, el operar de cada una de estas presunciones está regulada por diferentes virtudes epistémicas procedimentales. En Vértigos enumero la contrastabilidad empírica, el poder predictivo, el poder explicativo y la coherencia (o tal vez, mejor, la consistencia). Por supuesto, cada una de estas virtudes posee una compleja historia: las virtudes que enumero y cómo las 
caracterizo dependen de la cultura científica que se comienza a producir poco a poco alrededor del siglo XVI.

Pero vayamos a las reglas inferenciales. En relación con un modelo mixto, tengo sobre éstas mis mayores dudas. En Vértigos señalo que las reglas inferenciales constitutivas son aquellas que expresan cómo tienen que conectarse las premisas con la conclusión, para apoyarla: prescriben cuándo, tomando las premisas juntas, ello es suficiente material para aceptar la conclusión. Pero hay varias maneras en que se puede decir tal cosa: disponemos de conexiones tanto determinadas como subdeterminadas. La conexión determinada es la deducción y, así, constituye un "caso límite" de apoyo inferencial por lo menos en tres sentidos. En primer lugar, se trata del "ideal": una o varias premisas apoyan deductivamente a una conclusión si es imposible que la última sea falsa cuando las primeras son verdaderas. En segundo lugar, se trata de un "caso límite" en tanto un "grado de abstracción": se juzga un argumento teniendo en cuenta sólo la relación entre ciertas premisas explícitas y una conclusión explícita (se maneja, pues, un concepto puramente atómico de argumento); así, entre otros, difícilmente se podrían aceptar los argumentos de reducción al absurdo. En tercer lugar, se trata de un "caso límite" en tanto "fin" de una discusión: cuando se procede a deducir en los debates no formales casi todas las tareas argumentales ya han sido realizadas: las premisas se han obtenido mediante inducciones o analogías... que conforman las conexiones subdeterminadas de apoyar premisas. En cuanto a las reglas regulativas de las reglas inferenciales, éstas serían el resto de las otras reglas regulativas.

Si no me equivoco esta reconstrucción de la argumentación que toma como punto de partida la disputatio sería un modelo mixto de argumentación: por un lado, hay normas universales tanto de constitución de conceptos (por ejemplo, del concepto de argumentación) como de normas de razonamiento, pero su aplicación (una tarea que no es totalmente externa a la formulación de las normas) es siempre contextual. Por otro lado, hay normas contextuales en el sentido de "históricamente atrincheradas" como las virtudes epistémicas.

3. Sergio Martínez se admira de que no tenga en cuenta al confiabilismo cuando discuto el proyecto de un antifundamentalismo amplio o multifundamentalismo. Tiene razón, pues lo que defiendo tiene mucho que ver con algunas formas de confiabilismo. Para los confiabilistas, como recuerda Martínez, para que una creencia cuente como justificada debe ser el resultado de un proceso "confiable": un proceso confiable es un proceso que generalmente produce creencias verdaderas. La dificultad es que hay muchas clases de confiabilismo. Un confiabilismo "puramente" externalista afirmaría: $P$ sabe que $p$ si y sólo si $p$ es verdadera y obtenida por un proceso 
confiable, aunque frente a dudas sobre $p, P$ no tenga la menor idea de qué responder ( $P$ ignora totalmente de qué va en ese proceso confiable). Yo no estaría de acuerdo con este confiabilismo que ubica a las justificaciones del saber totalmente fuera del "espacio de las razones", para usar la conocida frase de Sellars. En cambio, tengo simpatías por un confiabilismo que sitúa a los procesos confiables --usando esta expresión en enfático y heterogéneo plural- dentro del "espacio de las razones": un espacio de normatividad en el que están presentes tanto normas universales como normas históricamen. te atrincheradas a la manera de las virtudes epistémicas.

4. Sergio Martínez observa que al trazar una fenomenología de la argumentación no tomo en cuenta los estudios psicológicos pertinentes: me conformo con los recursos de un médico de cabecera cuando también es posible recurtir a exámenes clínicos para elaborar el diagnóstico. De nuevo, tiene razón. Pero así como los recursos de un médico de cabecera son inevitablemente el primer paso, también me resulta la fenomenología este primer paso para indicar que en la argumentación $-y$, en general, en la vida mentalrige también algo así como una ley de la inercia. Que argumentar no es, pues, un conductor de comprensión, verdad y valor, sólo un promotor; un promotor que hay que complementar con otros promotores, como la percepción o, con Aristóteles y Hegel, los buenos hábitos y las buenas instituciones (todo el reino in de Popper y muchos elementos más). Incluso para dioses que argumentaran perfectamente, la argumentación sería sólo un pro. motor que necesita de otros promotores de comprensión, verdad y valor, so pena de sucumbir en vértigos argumentales.

5. Conozco la reciente mala fama que posee distinguir la forma del contenido de algo. Pese a ello, me refiero a "puntos de vista formales" y a "vértigos formales". Hablo de "puntos de vista formales" no tanto para subrayar modos de estructuración que son independientes de todo contexto, como para aludir a modos de estructuración que son relativamente independien. tes del contenido que articulan y organizan, abstrayendo en algún grado de esos contenidos. Los puntos de vista formales serían, de este modo, mecanismos de estructuración -de articulación y organización- de diferentes tipos de contenido. La relación entre forma y contenido sería aquí pensada a partir de la relación entre el funcionamiento de un dispositivo y sus resultados, o si se prefiere, a partir de la relación de un mecanismo con sus productos. O usando una analogía parcial pero, creo, no del todo desencaminada: los puntos de vista formales lo son en el sentido en que es formal cualquier esquema que, al abstraer en parte algunos contenidos, sirve como esquema de varios contenidos. Pero los esquemas no tienen por qué ser universales y necesarios: son esquemas en relación con ciertos contenidos. En este punto hay todavía mucho por aclarar. 
6. Regreso al comienzo. Sergio Martínez se alarma de mi "prejuicio analítico" al temer reducir los varios tipos de justificación a prácticas contingentes de la justificación, prácticas socialmente aceptadas en cierto grupo y en cierto tiempo y solo por ello aceptables. Yo diría que en este caso, mi "prejuicio" expresa sólo el temor a sucumbir en el relativismo más desaforado, más salvaje. Esto es, no quiero reducir la razón y sus procesos a meras modas históricas circunstanciales, reducción que en último término nos obligaría a reducir todos los procesos del saber, de cualquier normatividad y sus varias instituciones a simples maniobras del poder en turno, "deconstruyendo" así a la razón como una útil máscara del poder. ¿Es posible resistir este vértigo simplificador, estas reducciones, sin comprometerse con otros vértigos igualmente simplificadores, con los modelos a priori? Mi propuesta para escapar al dilema que llamé el "obstáculo de Martínez" son los modelos mixtos: construir un pensamiento que, a la vez, respete los requerimientos de la razón y los de la historia, que sea atento a nuestros presupuestos necesarios y a los vastos territorios de la contingencia y sus atrincheramientos. Se trata de mostrar que el tiempo transcurrido no es el simple campo de la contingencia, que la tradición puede ser algo más que una secuela de arbitrariedades. Se busca, entonces, defender que en la historia de vez en cuando también se descubren las huellas, a veces incluso muy profundas y decisivas, de una razón enfáticamente normativa. 